\title{
A Participação Social na Implantação do Curso de Licenciatura em Educação do Campo na Universidade Federal de Santa Catarina
}

\section{Social Participation in the Implementation of the Undergraduate Course in Rural Education at the Federal University of Santa Catarina}

Katia Denise Moreira

Secretária Executiva da Universidade Federal de Santa Catarina (UFSC)

Doutoranda PPGA da Universidade Federal de Santa Catarina (UFSC)

http://lattes.cnpq.br/5060813594042823

orcid.org/0000-0003-1946-8423

katia.denise@ufsc.br

Luci Mari Aparecida Rodrigues

Secretária Executiva da Universidade Federal de Santa Catarina (UFSC)

Mestranda em Administração PPGA da Universidade Federal de Santa Catarina (UFSC)

http://lattes.cnpq.br/6255847958775563

orcid.org/0000-0002-7307-2078

luci.mari@ufsc.br

llane Frank Dias

Professora da Faculdade Capivari (FUCAP)

Doutoranda PPGA da Universidade Federal de Santa Catarina (UFSC)

http://lattes.cnpq.br/6915167017529506

orcid.org/0000-0003-1689-9295

ilanefrank@gmail.com

Resumo: Atender as singularidades da educação no campo é um ato social urgente. Nesse sentido, este estudo de caso apresenta uma análise de como aconteceu o processo da participação social na implantação do Curso de Graduação em Licenciatura em Educação no Campo da Universidade Federal de Santa Catarina. Trata-se de uma pesquisa de abordagem qualitativa e em relação às técnicas de coleta de dados, utilizou-se a bibliográfica, a documental e entrevistas semiestruturadas, com seis atores sociais envolvidos, diretamente, com o Curso. Como categorias de análise optou-se pelos critérios de avaliação da qualidade democrática dos processos participativos, Castellà e Parés (2012), com foco nas dimensões “Quem participa?" e "Sobre o que se Participa?". Os resultados da pesquisa apontaram que os critérios citados foram contemplados no momento da implantação do curso. No entanto, constatou-se que atualmente ocorre um distanciamento dos movimentos sociais em relação ao acompanhamento das políticas e ações inerentes ao curso.

Palavras-chave: Gestão Social; Participação; Educação no Campo.

Abstract: Addressing the singularities of rural education is an urgent social act. Thus, this case study presents an analysis of how the process of social participation in the implementation of the undergraduate course in rural education at the Federal University of Santa Catarina (UFSC) occurred. This is a qualitative research and to collect data, the following methods were used: bibliographical research, documentary analysis and semi-structured interviews with six social actors directly involved with the undergraduate course. As categories of analysis, we opted for the criteria for evaluating the democratic quality of participatory processes, by Castellà and Parés (2012), focusing on two dimensions: "Who participates?" and "What do they participate in?". The results of the survey indicated that the criteria above had been contemplated when the course was implemented. However, it was observed that, currently, there is an estrangement of social movements in relation to the close monitoring of policies and actions inherent to the course.

Key words: Social Management; Participation; Rural Education.

Texto completo em português: http://www.apgs.ufv.br Full text in Portuguese: http://www.apgs.ufv.br

\section{INTRODUÇÃo}

A partir da premissa de que todo cidadão possui direitos e deveres, reflete-se sobre a participação dos indivíduos nos processos políticos, econômicos e sociais de um país e a possibilidade deste processo participativo servir de elo entre o Estado e a sociedade. Concordam com essa perspectiva Castellà e Parés (2012, p. 210) quando mencionam que "[...] é preciso contar com os cidadãos na hora de tomar decisões coletivas".

A este contexto se inserem os processos de criação de cursos de graduação em instituições públicas de ensino superior e para este estudo, especificamente, o caso do Curso de Graduação em
Licenciatura em Educação do Campo, que foi implantado no ano de 2009, na Universidade Federal de Santa Catarina (UFSC), o qual tem por finalidade atender às demandas diferenciadas da área da educação, principalmente as relativas às singularidades do campo e outras necessidades específicas em regiões caracterizadas pela diversidade social. Considerado tal contexto, questiona-se: como aconteceu o processo da participação social na implantação do Curso de Graduação em Licenciatura em Educação do Campo da UFSC?

A fim de responder tal questionamento, esta pesquisa analisará como aconteceu o processo da participação social na implantação 
do Curso de Graduação em Licenciatura em Educação do Campo, ou seja, se a participação dos atores sociais envolvidos no processo atendeu a qualidade democrática dos processos administrativos, uma vez que, o curso nasce de uma reivindicação da comunidade do campo.

Para atingir o propósito deste estudo foram delineados quatro eixos estruturantes: i) conhecer as especificidades da educação no campo; ii) averiguar como se deu a política e o processo de implantação do Curso de Graduação em Educação do Campo e iii) verificar se houve o alinhamento entre a implantação do curso e a participação social, os quais foram trabalhados sob uma perspectiva qualitativa.

Justifica-se a escolha do caso, por ser imperioso tratar das questões sociais do campo, principalmente aquelas relativas à educação no contexto do aprimoramento das relações entre a universidade e a sociedade, além de conhecer o processo de implantação de cursos que têm suas origens no comprometimento com a transformação das condições de educação do povo brasileiro residente no campo.

Por fim, o artigo compreende em sua estruturação a exposição geral do tema nesta introdução, em seguida, passa-se aos aportes teóricos que embasaram o estudo e caracteriza-se a metodologia adotada, para então, fazer-se a apresentação dos dados, caracterizando-os no contexto do caso escolhido. Depois, a análise e discussão dos resultados da pesquisa é feita e, por fim, são apresentadas as conclusões dos autores e as referências utilizadas.

\section{FUNDAMENTAÇÃO TEÓRICA}

\subsection{A GESTÃO SOCIAL E A PARTICIPAÇÃO CIDADÃ}

Para fins de contextualização neste estudo, a gestão social apresenta-se como a "tomada de decisão coletiva, sem coerção, baseada na inteligibilidade da linguagem, na dialogicidade e no entendimento esclarecido como processo, na transparência como pressuposto e na emancipação enquanto fim último" (Cançado, Sausen \&Villela, p. 17, 2013).

A gestão social caracteriza-se ainda como um processo gerencial participativo em que o processo decisório é exercido por meio de diferentes sujeitos sociais, isto é, as decisões são oriundas do coletivo, havendo a busca pelo atendimento das demandas e necessidades sociais (Cançado, Sausen \&Villela, 2013). A dimensão econômica consiste em um meio para a obtenção da finalidade social. Essa prática gerencial não ocorre com tranquilidade, especialmente em virtude da expansão da lógica mercantil e a hegemonia dos instrumentos de processo gerencial com conteúdo da gestão privada, entremeando as demais práticas de gestão.

Nesse contexto, a gestão social foi escolhida, nesta pesquisa, como dimensão de fundamento da participação do individuo na sociedade. Os conceitos desse tipo específico de gestão direcionam o contexto da participação para o âmbito da cidadania que, por sua vez, considera os direitos sociais mais amplos. A soma destes dois elementos - participação e cidadania - em termos de gestão social é denominada Cidadania Deliberativa.
A ideia central de Cidadania Deliberativa, apresentada por Tenório (1999), baseia-se nos argumentos teórico-sociais de Habermas (1995), que a apresenta como "terceira concepção procedimental de política deliberativa". Nesse conceito a Cidadania Deliberativa considera o cidadão como um indivíduo democraticamente ativo, que pode transformar a sua própria situação social. Essa concepção vem para complementar as ideias de cidadania liberal, que reconhece o cidadão como aquele que possui direitos coletivos em prol dos seus direitos privados, e cidadania republicana, na qual o cidadão é um ator político.

No que se refere à efetividade da cidadania deliberativa, Tenório (1999) considera que para atuar com inovação e democracia, os governos locais devem reconhecer a capacidade da comunidade, o foco da cidadania no processo, a compreensão dos valores da comunidade, a delegação do poder para aqueles que estão na operação e a descaracterização da tecno-burocracia para uma perspectiva de cidadão-funcionário.

Dialogicamente, a participação do sujeito pode ser tipificada por meio dos conceitos da Escada de Participação apresentada por Arnstein (2002), que a aborda sob a perspectiva do poder cidadão. Trata-se de uma escada com oito degraus, na qual diferentes níveis de poder são dados ao cidadão, classificados em três grupos: a) a "não participação" - degraus de manipulação e terapia; b) "nível de concessão mínima de poder" - degraus de informação, consulta e pacificação e c) "poder cidadão" - degraus de parceria, delegação de poder e controle cidadão. Observa-se que na participação sem poder (degraus do nível um e dois) os tomadores de decisão [legítimos] asseguram-se de que todas as partes interajam, de que todos os lados sejam ouvidos, entretanto poucos são beneficiados (Arnstein, 2002). A autora alerta ainda para pontos críticos da participação cidadã, como o separatismo e o poder das bases sem a garantia de impacto global, e reconhece que tais pontos sempre existiram, assim como a tomada de poder pelos excluídos.

Inspirados pela teoria de Arnstein (2002), Castellà e Parés (2012) desenvolveram estudo no sentido de avaliar a qualidade democrática dos processos participativos e, assim sendo, criaram categorias de análise que permitissem alcançar tal propósito, as quais estão dispostas no Quadro 1.

Quadro 1: Aspirações normativas e critérios de avaliação da qualidade democrática dos processos participativos.

\begin{tabular}{|c|c|c|}
\hline Âmbitos & Aspiração Normativa & Dimensões \\
\hline \multirow{7}{*}{$\begin{array}{l}\text { A coordenação } \\
\text { do processo }\end{array}$} & \multirow{7}{*}{$\begin{array}{l}\text { Um processo participativo de } \\
\text { qualidade deveria contar com } \\
\text { o apoio político, administrativo } \\
\text { e social às suas necessidades } \\
\text { e à metodologia de } \\
\text { desenvolvimento; um trabalho } \\
\text { interno transversal; o } \\
\text { compromisso político da } \\
\text { implementação de seus } \\
\text { resultados e uma liderança } \\
\text { compartilhada. Além disso, } \\
\text { deveria te objetivos } \\
\text { claramente definidos; dispor } \\
\text { de recursos (humanos, } \\
\text { materiais de informação e } \\
\text { tempo) apropriados para seu } \\
\text { desenvolvimento; e estar } \\
\text { integrado, na medida do } \\
\text { possível, ao sistema } \\
\text { participativo do município. }\end{array}$} & $\begin{array}{lll}\text { Acordo político, social } & \text { e } \\
\text { administrativo sobre } & \text { a } \\
\text { necessidade de realizar } & \text { o } \\
\text { processo e sua metodologia. }\end{array}$ \\
\hline & & Transversalidade interna. \\
\hline & & $\begin{array}{l}\text { Compromisso político claro em } \\
\text { relação à implementação dos } \\
\text { resultados. }\end{array}$ \\
\hline & & $\begin{array}{l}\text { Liderança compartilhada do } \\
\text { processo participativo. }\end{array}$ \\
\hline & & $\begin{array}{l}\text { Integração e coordenação do } \\
\text { processo com o sistema } \\
\text { participativo do município. }\end{array}$ \\
\hline & & Definição clara de objetivos. \\
\hline & & 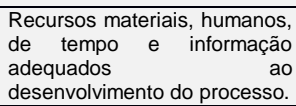 \\
\hline $\begin{array}{c}\text { Quem } \\
\text { participa? }\end{array}$ & $\begin{array}{l}\text { A participação em um } \\
\text { processo de qualidade deveria } \\
\text { ser a mais ampla e }\end{array}$ & $\begin{array}{l}\text { Amplo envolvimento dos } \\
\text { participantes. }\end{array}$ \\
\hline
\end{tabular}




\begin{tabular}{|c|c|c|}
\hline $\begin{array}{c}\text { Os } \\
\text { participantes }\end{array}$ & $\begin{array}{l}\text { representativa possível do } \\
\text { conjunto de cidadãos a que se } \\
\text { dirige em relação à diversidade } \\
\text { de perfis de participantes e à } \\
\text { diversidade dos discursos } \\
\text { existentes na população, } \\
\text { referentes ao tema tratado. }\end{array}$ & $\begin{array}{l}\text { Diversidade de participantes } \\
\text { (grupos sociais e discursos). }\end{array}$ \\
\hline \multirow{3}{*}{$\begin{array}{l}\text { Sobre o que se } \\
\text { participa? }\end{array}$} & \multirow{3}{*}{$\begin{array}{l}\text { O processo participativo de } \\
\text { qualidade deveria fazer } \\
\text { referências a questões } \\
\text { políticas relevantes, a temas } \\
\text { sobre os quais a administração } \\
\text { local tenha capacidade de } \\
\text { intervenção e que, na medida } \\
\text { do possível, procedam de uma } \\
\text { reivindicação cidadã. }\end{array}$} & $\begin{array}{l}\text { Relevância política do tema } \\
\text { em que se concentra o } \\
\text { processo participativo. }\end{array}$ \\
\hline & & $\begin{array}{l}\text { Capacidade de intervenção da } \\
\text { administração local sobre o } \\
\text { tema. }\end{array}$ \\
\hline & & $\begin{array}{l}\text { Tema oriundo de reivindicação } \\
\text { cidadã. }\end{array}$ \\
\hline \multirow{4}{*}{$\begin{array}{l}\text { Como se } \\
\text { participa? }\end{array}$} & \multirow{4}{*}{$\begin{array}{l}\text { Um processo participativo de } \\
\text { qualidade deve possibilitar que } \\
\text { seus participantes deliberem } \\
\text { em condições de igualdade, } \\
\text { tenham capacidade de fazer } \\
\text { propostas e, finalmente, } \\
\text { tomem uma decisão de forma } \\
\text { democrática. Além disso, o } \\
\text { processo deveria poder ser } \\
\text { avaliado desde seu início e de } \\
\text { forma contínua. }\end{array}$} & $\begin{array}{l}\text { Grau de participação dos } \\
\text { participantes no processo: } \\
\text { tomada de decisão. }\end{array}$ \\
\hline & & $\begin{array}{l}\text { Capacidade de proposta dos } \\
\text { participantes do processo. }\end{array}$ \\
\hline & & $\begin{array}{l}\text { Deliberação em condições de } \\
\text { igualdade: uso de técnicas } \\
\text { participativas. }\end{array}$ \\
\hline & & Avaliação do próprio processo. \\
\hline \multirow{5}{*}{$\begin{array}{l}\text { Os resultados } \\
\text { do processo }\end{array}$} & \multirow{5}{*}{$\begin{array}{l}\text { Um processo participativo de } \\
\text { qualidade deve ter resultados } \\
\text { substantivos que comportem } \\
\text { uma influência real dos } \\
\text { cidadãos sobre as decisões } \\
\text { públicas } 4 \text { (resultados } \\
\text { substantivos) erum } \\
\text { fortalecimento da rede de } \\
\text { atores que intervieram no } \\
\text { processo (resultados } \\
\text { relacionais). Esses resultados } \\
\text { devem retornar aos } \\
\text { participantes para que estes } \\
\text { possam fazer o } \\
\text { acompanhamento. Além disso, } \\
\text { o processo deve favorecer a } \\
\text { capacitação dos participantes } \\
\text { em uma cultura política } \\
\text { participativa. }\end{array}$} & $\begin{array}{l}\text { Obtenção de resultados } \\
\text { substantivos que respondam } \\
\text { às necessidades propostas no } \\
\text { estabelecimento do processo. }\end{array}$ \\
\hline & & $\begin{array}{l}\text { Fortalecimento das relações } \\
\text { entre os diferentes atores. }\end{array}$ \\
\hline & & $\begin{array}{l}\text { Implementação dos resultados } \\
\text { substantivos e o impacto real } \\
\text { na definição de políticas } \\
\text { públicas. }\end{array}$ \\
\hline & & $\begin{array}{l}\text { Retorno dos resultados ao fim } \\
\text { do processo. }\end{array}$ \\
\hline & & $\begin{array}{l}\text { Capacitação dos participantes } \\
\text { do processo. }\end{array}$ \\
\hline
\end{tabular}

Fonte: Castellà e Parés (2012).

Identifica-se que os autores que militam nessa linha de gestão defendem a ação de dar poder aqueles que estão nas bases da sociedade, manifestando a aspiração de transformar o cidadão em alguém que pode modificar a sua própria realidade social, alinhando-se assim aos pressupostos da Cidadania Deliberativa. Todavia, há de se alertar sobre a visão de cidadania a partir da simples concessão de poder ao cidadão, sem avaliar o seu grau de envolvimento nos resultados de forma efetiva.

\subsection{BREVES CONSIDERAÇÕES SOBRE RACIONALIDADES E SUA INFLUÊNCIA NO CAMPO}

É fato histórico que a busca do homem pelo progresso a partir dos inventos tecnológicos trouxe muitas facilidades e benefícios para a vida da humanidade. A ciência expandiu-se em diferentes áreas e a vida em sociedade passou a ser objeto de estudo e de regulamentação por parte de seus integrantes.

Criaram-se assim, organizações sociais, econômicas, jurídicas e políticas para atender às necessidades inerentes ao ser humano enquanto ser social. $O$ homem passou de ser singular a ser plural e, assim, o privado foi se tornando menos denso, dando lugar ao público, e os desejos de consumo passaram a ser coletivos.

A partir de tal processo "[...] as organizações formais peculiares à atual sociedade centrada no mercado acabaram por assumir o caráter de um paradigma para a organização da existência humana de maneira geral” (Cruz Júnior, 1988, p. 4).

Da mesma maneira, Guerreiro Ramos (1989) registra a sociedade como mercadocêntrica, ou seja, que se reconhece apenas como representativa de organizações econômicas, centrada e subordinada às regras do mercado. Entretanto, contesta a visão unidimensional de organização como sistema centrado no mercado, que percebe o indivíduo que a compõe apenas com critérios de produtividade. A esta visão ele chama de racionalidade funcional ou instrumental.

Em contraponto ao posto, está à racionalidade substantiva que, para Guerreiro Ramos (1989), é determinada pela crença consciente em valores éticos, estéticos, religiosos ou sob qualquer outra forma em que se manifestem próprios e absolutos de uma conduta, sem relação alguma com o resultado. Para o autor, a racionalidade substantiva também se caracteriza pela ação afetiva, especialmente emotiva, determinada por afetos, por estados sentimentais do momento e pela ação tradicional, esta determinada por um costume arraigado.

No sentido social da existência de diversas racionalidades, Guerreiro Ramos (1989) faz críticas a essas abordagens funcionalistas e consequentemente às organizações que atuam em uma sociedade centrada no mercado, identificando o que ele chamou de síndrome comportamentalista. Esta síndrome é vista como "uma disposição socialmente condicionada, que afeta a vida das pessoas quando estas confundem as regras e normas de operação peculiares a sistemas sociais episódicos com regras e normas de sua conduta como um todo" (Guerreiro Ramos, 1989, p. 52). Logo, os objetivos econômicos passam a dominar as esferas da vida humana, fazendo com que os indivíduos utilizem noções de lucro, produtividade, eficiência e eficácia.

Defendendo a teoria da existência de uma organização produtiva sem as motivações econômicas, Polanyi (2000) apresenta dois princípios, o da reciprocidade e da redistribuição. A reciprocidade está presente nas relações da subsistência familiar, na qual o reconhecimento social será alcançado, mas os benefícios se dividem entre a família. Não há retorno material direto além da credibilidade, ou de descrédito, caso haja ação contrária. Já o princípio da redistribuição é o precursor para o surgimento da divisão do trabalho, nele há a centralização da atividade de distribuição da produção, por exemplo, quando uma parte da produção de uma comunidade é entregue para um chefe ou líder, que tem a função de armazená-la e distribuí-la em troca de favores diferenciados para a comunidade (Polanyi, 2000).

Nesse contexto, tem-se que a gestão social traz em sua essência a renúncia ao conceito de desenvolvimento como um sinônimo de industrialização, tratando-o como fonte de bem-estar social, para impulsionar assim a educação e a preservação ambiental (Cançado, Sausen \& Villela, 2013). Dessa forma, "os processos de democratização refletidos na capacidade de participação cidadã, na gestão social dos processos decisórios locais, poderão contribuir para o desenvolvimento multidimensional, logo, sustentável" (Cançado, Sausen \& Villela, 2013, p.27).

Esse desenvolvimento multidimensional dá sentido aos espaços geográficos, reconhecendo o domínio local de conhecimento específico, uma identidade de coesão social. Dá-se, então, margem ao conceito de Desenvolvimento Territorial Sustentável (DTS), que se apresenta como conceito interdependente à gestão social e à governança participativa. 
O desenvolvimento territorial sustentável pode trazer à tona o conflito entre as racionalidades, instrumental e substantiva, no campo, tais como o contexto estratégico versos o social. 0 desenvolvimento no campo vem notadamente acompanhado da agressiva cultura industrial, marcada pela alavancagem comercial do agrobusiness. No Brasil há poucas ações no sentido de desenvolver, local e socialmente, comunidades rurais, para que possam se desvencilhar das instituições dominantes (Brasil, 2007).

Logo, a racionalidade de mercado afeta diretamente as ações locais de desenvolvimento rural, e na medida em que afasta da ação racional substantiva, busca desenvolver as ações do campo de forma estratégica. É necessário, contudo, verificar localmente a existência e a manutenção de ações que buscam desenvolvimento social e sua efetividade.

\section{PROCEDIMENTOS METOdOLÓGICOS}

A pesquisa foi realizada com o objetivo de analisar como aconteceu o processo da participação social na implantação do Curso de Graduação em Licenciatura em Educação do Campo da UFSC, e foi conduzida como um estudo de caso interpretativo, visto que "busca encontrar padrões nos dados e desenvolver categorias conceituais que possibilitem ilustrar, confirmar ou opor-se às suposições teóricas" (Godoy, 2006, p.124).

No que se refere à abordagem, trata-se de análise qualitativa, descrita por Godoy (1995, p. 62), como aquela que "têm como preocupação fundamental o estudo e a análise do mundo empírico em seu ambiente natural. A pesquisa procura ainda compreender $o$ fenômeno estudado por meio da "obtenção de dados descritivos sobre pessoas, lugares e processos interativos pelo contato direto do pesquisador com a situação estudada, procurando compreender os fenômenos segundo a perspectiva dos sujeitos, ou seja, dos participantes da situação em estudo" (Godoy, 1995, p. 58).

No que diz respeito aos objetivos, a pesquisa é descritiva, que Vergara (2007, p. 47) caracteriza como aquela que "[...] expõe características de determinada população ou de determinado fenômeno. Pode também esclarecer correlações entre variáveis e definir sua natureza. Não tem compromisso de explicar os fenômenos que descreve, embora sirva de base para tal explicação".

Quanto à coleta de dados foram utilizadas as técnicas: bibliográfica, em material já consolidado sobre o tema, encontrado em livros e artigos científicos; documental, em atas, resoluções, leis e no projeto político pedagógico do curso em estudo; de campo, por meio de entrevistas semiestruturadas, definida por Oliveira (2007, p. 86) como aquela que "tem como principal objetivo compreender os significados que os entrevistados atribuem às questões e situações relativas ao tema de interesse". O recorte temporal são os anos de 2009 a 2014, em que os dados foram coletados em 2014.

Sobre o processo das entrevistas, foram realizadas seis, com atores sociais envolvidos diretamente com o curso de graduação em Licenciatura em Educação do Campo: a primeira coordenadora do curso (entrevistado E1), a atual coordenadora do curso (entrevistado E2) e egressos, pelo critério de acessibilidade, da primeira turma do curso (entrevistados E3, E4, E5 e E6), os quais foram questionados sobre a caracterização da educação do campo, o processo de estruturação do Curso e a participação da comunidade, especialmente aquela do campo, na implantação do curso. Sobre a escolha dos entrevistados, Vergara (2007) considera a intencionalidade da seleção dos entrevistados, estes são caracterizados como os atores sociais aptos a fornecer os dados que se necessita.

Os dados foram analisados por meio do método de análise de discurso, com base nos critérios de avaliação da qualidade democrática dos processos participativos de Castellà e Parés (2012), conforme disposto no Quadro 2.

Quadro 2: Aspirações normativas e critérios de avaliação da qualidade democrática dos processos participativos.

\begin{tabular}{|c|c|c|}
\hline Âmbitos & Aspiração Normativa & Dimensões \\
\hline \multirow{3}{*}{$\begin{array}{l}\text { Quem participa? } \\
\text { Os participantes }\end{array}$} & \multirow{3}{*}{$\begin{array}{l}\text { A participação em um } \\
\text { processo de qualidade } \\
\text { deveria ser a mais ampla } \\
\text { e representativa possível } \\
\text { do conjunto de cidadãos a } \\
\text { que se dirige em relação à } \\
\text { diversidade de perfis de } \\
\text { participantes e à } \\
\text { diversidade dos discursos } \\
\text { existentes na população, } \\
\text { referentes ao tema } \\
\text { tratado. }\end{array}$} & $\begin{array}{l}\text { Amplo envolvimento } \\
\text { dos participantes. }\end{array}$ \\
\hline & & $\begin{array}{l}\text { Diversidade de } \\
\text { participantes (grupos } \\
\text { sociais e discursos). }\end{array}$ \\
\hline & & $\begin{array}{l}\text { Representação de } \\
\text { atores. }\end{array}$ \\
\hline \multirow{4}{*}{$\begin{array}{l}\text { Sobre o que se } \\
\text { participa? }\end{array}$} & \multirow{4}{*}{$\begin{array}{l}\text { O processo participativo } \\
\text { de qualidade deveria } \\
\text { fazer referências a } \\
\text { questões políticas } \\
\text { relevantes, a temas sobre } \\
\text { os quais a administração } \\
\text { local tenha capacidade de } \\
\text { intervenção e que, na } \\
\text { medida do possível, } \\
\text { procedam de uma } \\
\text { reivindicação cidadã. }\end{array}$} & $\begin{array}{l}\text { Relevância política } \\
\text { do tema em que se } \\
\text { concentra o processo } \\
\text { participativo. }\end{array}$ \\
\hline & & $\begin{array}{lr}\text { Capacidade } & \text { de } \\
\text { intervenção } & \text { da } \\
\text { administração } & \text { local } \\
\text { sobre o tema. } & \end{array}$ \\
\hline & & $\begin{array}{l}\text { Tema oriundo de } \\
\text { reivindicação cidadã. }\end{array}$ \\
\hline & & $\begin{array}{lr}\text { Capacitação } & \text { dos } \\
\text { participantes } & \text { do } \\
\text { processo. } & \end{array}$ \\
\hline
\end{tabular}

Fonte: Castellà e Parés (2012).

Conforme apresentado no arcabouço teórico deste estudo, os autores apresentam cinco categorias de análise, no entanto optouse por utilizar como base da análise operacional somente duas dimensões "Quem participa?" e "Sobre o que se Participa?". Justifica-se tal escolha por se considerar que tais dimensões seriam as possíveis de serem verificadas, dado o limite temporal definido, a disponibilidade dos entrevistados e o objetivo proposto neste trabalho.

\section{ANÁLISE E DISCUSSÃo dOS RESULTADOS}

\subsection{O CONTEXTO DE ESTUDO}

A educação é um direito e um dever, conforme explica o disposto no artigo 205 da Constituição da República Federativa do Brasil (Brasil, 1988). Um direito de todos e dever do Estado e da família, que "[...] será promovida e incentivada com a colaboração da sociedade, visando ao pleno desenvolvimento da pessoa, seu preparo para o exercício da cidadania e sua qualificação para o trabalho" (Brasil, 1988). A esse contexto, insere-se a educação no campo, local que em território brasileiro:

[...] apresenta os mais baixos índices de escolaridade de toda a sociedade. $\mathrm{O}$ analfabetismo da população rural na faixa etária acima de 15 anos é de $32,7 \%$, enquanto que, somente $2 \%$ de jovens que moram no campo, frequentam o ensino médio $O$ que demonstra a negação - à população do campo - do direito de acesso e 
permanência na escola para completar sua formação inicial (Anhaia, 2010, p 5)

O Instituto Brasileiro de Geografia e Estatística (IBGE) (2012) divulgou que os índices do analfabetismo da população rural na faixa etária de 15 anos ou mais é de $21,1 \%$, enquanto que, na área urbana o percentual é consideravelmente menor, de 6,6\% (IBGE, 2012).

Em termos de histórico da educação no campo, em 1998 foi realizada a I Conferência Nacional Por Uma Educação Básica do Campo. O objetivo era "[...] ajudar a recolocar o rural, e a educação que a ele se vincula, na agenda política do país" (Organização das Nações Unidas para a Educação, a Ciência e a Cultura [UNESCO], 1998 , p. 4), ou seja, o intuído era fazer com o que o governo revertesse à ideia exclusiva e desigual que havia da "sociedade" sobre o indivíduo que vive no campo.

Tendo em vista o panorama descrito, no ano de 2001 diversos movimentos e entidades, tais como: a Confederação Nacional dos Trabalhadores na Agricultura (CONTAG), o Movimento de Organização Comunitária (MOC/BA), a União Nacional das Escolas Famílias Agrícolas do Brasil (UNEFAB), o Grupo de Trabalho de Reforma Agrária da UNB (GT/UnB), a Escola de Formação da CUT Amazônia, entre outros, estabeleceram a Proposta de Diretrizes Operacionais para a Educação Rural no Brasil, "no intuito de contribuir para a elaboração das Diretrizes Operacionais para a Educação Rural no Brasil” (Anhaia, 2010, p 3).

A partir das ações reivindicativas da população que vive no campo, o Governo Federal, em 2001, por meio da Câmara de Educação Básica do Conselho Nacional de Educação, aprovou o Parecer $n ³ 6$, de 04 de dezembro de 2001, que trata das Diretrizes Operacionais para a Educação Básica nas Escolas do Campo. Em 3 de abril de 2002 é publicada a Resolução no 1, que institui tais diretrizes.

A Resolução ํo 2, de 28 de abril de 2008, da Câmara de Educação Básica, estabelece diretrizes complementares, normas e princípios para o desenvolvimento de políticas públicas de atendimento da Educação Básica do Campo. O Decreto № 7.352, de 4 de novembro de 2010, dispõe sobre a política de educação do campo e o Programa Nacional de Educação na Reforma Agrária (PRONERA) (Instituto Nacional de Colonização e Reforma Agrária [INCRA], 2014). Vale destacar em relação à educação no campo,

Ela nasceu comprometida com a transformação das condições de vida do povo brasileiro que vive no campo. Sua perspectiva e contribuir para promover mudanças estruturais neste território, cuja vinculação com a cidade é inexorável. Superar a dicotomia inventada: compreender as profundas interrelações campo-cidade desvelar a conexão local global são parte dos desafios postos à Educação do Campo. A concepção de educação vinculada a este conceito não pode prescindir da necessária ligação com o contexto no qual se desenvolvem estes processos formativos: com os conflitos que perpassam o rural brasileiro, em função dos diferentes interesses econômicos e sociais para utilização deste espaço. (Molina, 2009, p. 15)

Nesse sentido, entende-se que a educação formal assume o compromisso de contribuir articulando as práticas empíricas aos conhecimentos científicos, não o inverso, como erroneamente esta acontecendo na maioria das práticas pedagógicas das Escolas do Campo (Paraná, 2006). A partir de tais reflexões compreende-se que as singularidades presentes na educação no campo são essenciais, visto que é interessante envolver aquilo que relaciona a teoria às práticas cotidianas específicas dos alunos que habitam no campo.

Partindo de tal pressuposto, nasce a proposta do curso de graduação em Licenciatura em Educação do Campo, implantado desde 2006, por meio de um projeto-piloto, nas Universidades Federais de Brasília, no Distrito Federal, e nos estados de Minas Gerais, Sergipe e Bahia, que atenderam a proposta do Ministério da Educação (MEC), por intermédio da Secretaria de Educação Superior (SESu) e da Secretaria de Educação Continuada Alfabetização e Diversidade (SECAD) (E1, 2014). A entrevistada destaca ainda que a proposta foi formulada para atender a escolarização dos anos finais do ensino fundamental e ensino médio nas escolas do campo.

Assim, tendo como foco o contexto apresentado e o estimado pelo MEC de que o Brasil precisa formar no mínimo vinte mil professores devidamente especializados para atender as escolas rurais (Universidade Federal de Santa Catarina [UFSC], 2013a), a Universidade Federal de Santa Catarina, em 1 de abril de 2009, por meio da Resolução n.ำ006/CEG/2009, de 01 de abril de 2009, criou o curso de graduação em Educação do Campo, modalidade Licenciatura, oferecido pelo Centro de Ciências da Educação (UFSC, 2013a), tendo como objetivo propiciar a formação de educadores para atuação na educação básica, especificamente para as séries finais do Ensino Fundamental e para o Ensino Médio, em escolas do campo, aptos a fazer a gestão de processos educativos e a desenvolver estratégias pedagógicas que visem à formação de sujeitos humanos autônomos e criativos, capazes de produzir soluções para questões inerentes à sua realidade, vinculadas à qualidade social do desenvolvimento de áreas rurais (UFSC, 2013a).

O curso foca as áreas de Ciências da Natureza e Matemáticas e Ciências Agrárias (E1, 2014), distribuídas em quatro anos de curso. Quanto à estrutura pedagógica, o curso está organizado em regime semestral, com uma carga mínima de 3.888 horas (Tempouniversidade de 3.096 horas; Tempo-comunidade de 648 horas, mais 144 horas em disciplinas optativas e atividades artísticoculturais), distribuídas em oito semestres, ou seja, quatro anos (UFSC, 2014). Em função daquilo que propõe a educação do campo e do perfil pretendido para os acadêmicos, o curso adota o "regime de alternância, com as atividades articuladas em dois tempos: universidade e comunidade" (UFSC, 2014, n.p).

Em razão das características do curso, o processo seletivo dáse de forma diferenciada, isto é, o concurso vestibular é específico e realizado em período diverso aquele estipulado para os demais cursos da UFSC $(E 1,2014)$. Para candidatar-se a essas vagas o indivíduo deve apresentar um perfil voltado à educação do campo, por exemplo, professores que estejam atuando em escolas do campo e que não possuem a "formação inicial" (graduação universitária, que é, hoje, a titulação mínima exigida), em outras palavras, os chamados "não habilitados", jovens inseridos nos movimentos sociais, que concluíram o ensino médio e que podem melhorar os processos educativos em suas regiões. Professores que já possuem formação universitária, mas pretendam ampliar seus conhecimentos nas áreas de formação e interessados em 
trabalhar no campo e na perspectiva de valorização do campo também podem se candidatar. (UFSC, 2013a).

Os acadêmicos, depois de concluído o curso, são outorgados com o grau de Licenciado em Educação do Campo nas áreas de Ciências da Natureza e Matemática e Ciências Agrárias (UFSC, 2013a). Nesse contexto, ressalta-se que a primeira turma do curso de graduação em educação do campo formou-se em 6 de setembro de 2013, sendo a cerimônia realizada na UFSC. Na ocasião, nove, dentre os 20 alunos que ingressaram no curso colaram grau (UFSC, 2013b).

O curso, além dos recursos da UFSC, conta com o apoio da SECAD e do MEC, via ProCampo, para os alunos (hospedagem, alimentação e deslocamentos entre os locais de trabalho e a UFSC) (E1, 2014).

Importante dizer que existem outras duas turmas de Licenciatura em Educação no Campo no estado de Santa Catarina, mais especificamente, nas cidades de: Canoinhas, onde há uma pareceria com o Instituto Federal de Santa Catarina (IFSC), e em Santa Rosa de Lima $(E 1,2014)$. Destaca-se a divulgação do curso na cidade de Canoinhas que, além de realizada por meios digitais e rádio, foi noticiada pelo Sindicato de Trabalhadores Rurais:

[...] uma oportunidade especial para jovens e interessados em buscar um aperfeiçoamento está sendo oferecida em todo o Planalto Norte Catarinense. Estão abertas as inscrições para o concurso vestibular da Universidade Federal de Santa Catarina (UFSC) para o curso de Licenciatura Plena em Educação do Campo e as aulas serão ministradas em Canoinhas. A notícia foi dada na manhã de terça-feira, 02, em um encontro promovido pelo Sindicato de Trabalhadores Rurais de Porto União, direcionado a autoridades e lideranças (Castilho, 2011, n.p.).

Além das rádios comunitárias e sindicatos, outros locais como escolas, grupos de igreja e espaços mais diferenciados que possam existir na comunidade são utilizados para divulgação do curso (E1, 2014). Nesse sentido, observa-se o cuidado em fazer uso de meios de comunicação mais comumente utilizados pela comunidade do campo.

Segundo a entrevistada 1, dentre os municípios a serem prioritariamente atendidos, estão: Caçador, Campos Novos, Correia Pinto, Curitibanos, Fraiburgo, São José do Cerrito e Videira. Todavia, vale dizer que, atualmente, além desses, outros municípios como: Leblon Regis, Timbó Grande, Frei Rogério, Salto Veloso, Canoinhas, Major Vieira, Santa Tereza, Irineópolis, Mafra, Santa Rosa de Lima, Anitápolis, Orleans e São Bonifácio (E2, 2014), aderiram ao proposto pelo curso de graduação em Licenciatura e Educação do Campo.

Essencial lembrar que o curso foi implantado na UFSC a partir do Programa de Apoio a Planos de Reestruturação e Expansão das Universidades Federais (REUNI) (E1, 2014). Instituído pelo Decreto № 6.096, de 24 de abril de 2007 (REUNI, 2007), o curso é uma das ações que integram o Plano de Desenvolvimento da Educação (PDE), que tem por objetivo: "[...] criar condições para a ampliação do acesso e permanência na educação superior, no nível de graduação, para o aumento da qualidade dos cursos e pelo melhor aproveitamento da estrutura física e de recursos humanos existentes nas universidades federais, respeitadas as características particulares de cada instituição e estimulada à diversidade do sistema de ensino superior" (Brasil, 2007, p. 10).
Contudo, segundo o Entrevistado 1, apenas em alguns aspectos, especificamente na contratação de professores, o curso foi beneficiado pelo programa, fato que comprova o dito por Búrigo (2009 citada por Perardt, 2013, p.137). "O Programa REUNI configurou-se então como uma política de Governo, porém o ingresso das Universidades Federais não foi simplesmente uma opção, mas uma imposição velada por parte do Governo Federal", complementado por Perardt (2013, p. 137) "Havia metas, ações e prazos a serem cumpridos pelas IFES em um cronograma estipulado, onde o não cumprimento destas implicava no não recebimento de recursos".

Introduzidas as concepções que envolvem a educação do campo e a implantação do curso de Licenciatura em Educação do Campo na UFSC, passa-se, no capítulo seguinte, à análise da participação cidadã na criação de um curso idealizado para o atendimento de uma classe que, conforme dito anteriormente, apresenta os mais baixos índices de escolaridade no país.

\subsection{RESULTADOS DA PESQUISA}

A partir dos dados coletados, esta análise buscou avaliar, por meio de critérios de avaliação da qualidade democrática dos processos participativos já pré-definidos: "quem participa?" e "sobre o que se participa?", a participação dos sujeitos no processo de implantação do curso de graduação em Licenciatura em Educação do Campo.

Desse modo, tendo em vista que para um processo de qualidade a participação no critério "quem Participa?" ou quem são os participantes do evento, deveria "[...] ser a mais ampla e representativa possível do conjunto de cidadãos a que se dirige em relação à diversidade de perfis de participantes e à diversidade dos discursos existentes na população, referentes ao tema tratado" (Castellà \& Parés, 2012, p. 235), questionou-se as coordenadoras do curso e aos acadêmicos egressos do curso em estudo sobre o amplo envolvimento dos participantes, a diversidade dos participantes e a representação dos atores.

Nesse sentido, E1 (2014) destaca que no início do processo de planejamento sobre a implantação do curso "houve amplo envolvimento dos movimentos sociais". E3 (2014) aponta que "os alunos eram ouvidos desde a primeira fase". E6 (2014) comenta que "o curso tem sua base nas experiências de escolas de assentamentos e assentamentos do MST, e sempre a educação do campo foi pensada e discutida junto aos povos do campo". Na visão de E4 (2014) "Todos os alunos diretamente não, mas são representados por membros da turma" e E5 (2014) fala sobre a participação da gestão federal, representada pela universidade, bem como municipais: "na minha fase foi proposta da universidade, mas pude perceber na turma posterior a minha uma mobilização das autoridades e alguns indivíduos da comunidade para a implementação do curso no seu município".

A partir do exposto, quanto ao amplo envolvimento dos participantes, entende-se que o projeto, em seu princípio, teve amplitude, visto a participação dos movimentos sociais, conforme destacaram E1(2014) e E6 (2014). 
Sobre a diversidade dos participantes, esta "terá maior qualidade democrática se for capaz de incorporar a diversidade da sociedade em que se desenvolve, ou seja, se os diferentes grupos sociais e interesses tiverem representados" (Castellà \& Parés, 2012, p. 236). A partir dos dados apresentados, considera-se que a diversidade está contemplada, pois de acordo com os atores houve, no processo de implantação do curso, envolvimento das três esferas que envolvem o tema - gestão universitária, comunidade e política.

No que se refere à representação dos atores, em que é preciso "garantir que esses [atores] sejam realmente portadores de um discurso coletivo" (Castellà \& Parés, 2012, p. 235), questionou-se sobre o processo de informação entre os sujeitos envolvidos no processo. E3 (2014) fala sobre a disponibilidade da gestão: "o pessoal do curso vai até a comunidade e conta com a ajuda das lideranças dos movimentos sociais, lideranças comunitárias, pastoral da terra, PRONERA e outros". E6 (2014) diz que há uma "relação construída com os diferentes atores [que] tem demonstrado um processo [informação] positivo, pois nós estudantes nos tornamos como uma ponte entre comunidade e a universidade, há uma troca de conhecimentos e aumentam as possibilidades de novas experiências no âmbito escolar". E1(2014), E2 (2014) e E3 (2014) comentaram sobre o Fórum Estadual de Educação, ferramenta amplamente utilizada no processo de informação, conforme destaca E3 (2014), é "bastante utilizado por pessoas de várias partes do estado".

Considera-se após o exposto que o discurso proveniente da comunidade para a universidade e vice-versa acontece, entretanto não é possível, a partir dos dados colhidos, mensurá-lo. Contudo, apesar de a participação ser efetiva no momento de implantação do curso, atualmente, tal elemento não é tão presente, visto que, com o passar do tempo os movimentos sociais foram se afastando do curso.

Nesse sentido, E1 (2014) reconhece que "o desenho do curso, que está situado em Florianópolis, dificulta a participação” e E2 (2014) confirma o dito, comentando que "os movimentos sociais, hoje, não tem participação nenhuma no curso. Não porque eles não tenham espaço, mas porque há um distanciamento territorial considerável, uma vez que o curso tem sede em Florianópolis, no litoral catarinense, e os movimentos sociais estão concentrados no oeste do Estado". Outra argumentação para o distanciamento estaria "relacionada com a conjuntura política dos movimentos, que é mais social e humana, do que das ciências da natureza e matemáticas" (E2 (2014).

Conclui-se assim, que no processo de criação e, mais especificamente, de implantação do curso há indícios de participação cidadã, visto que, os sujeitos foram democraticamente ativos, tentando mudar sua própria situação social, neste caso, reivindicando por uma educação do campo qualificada, a qual, segundo os dados, foi acolhida.

Desse modo, acredita-se que os critérios de qualidade democrática sobre "quem participa?" foram contemplados, para a implantação, contudo, atualmente, tal afirmação não se sustenta, conforme motivos já expostos.
Dando sequência, outro âmbito avaliado foi "sobre o que se participa?", que tem como aspiração normativa "O processo participativo de qualidade deveria fazer referência a questões políticas relevantes, a temas sobre os quais a administração loca tenha capacidade de intervenção e, na medida do possível, procedam de uma reivindicação cidadã" (Castellà \& Parés, 2012, p. 238). Desse modo, tendo como base as dimensões dos autores, os sujeitos da pesquisa foram questionados sobre a relevância política do tema em que se encontra o processo participativo, a capacidade de intervenção da administração local sobre o tema e se o tema era oriundo de uma reivindicação cidadã.

Em relação à relevância política da matéria, indagou-se primeiro, aos atores, se eles entendiam a implantação do curso como uma política estratégica governamental apenas para atender a legislação superior, até mesmo aquilo que determinava o programa REUNI, ou a uma política social, com vista a atender uma requisição cidadã.

E1 (2014) manifesta-se dizendo que "a implantação do curso atende questões tanto estratégicas, quanto sociais" e complementa dizendo "social porque surgiu da demanda de falta de professores para atuarem na educação do campo e estratégica porque a Lei de Diretrizes e Bases da Educação (LDB) exige, hoje, formação superior para docência". Ainda, quanto ao social, E2 (2014) aponta que a formação do Licenciado em Educação do Campo está voltada para o social, pois, se tenta pensar a escola do campo articulada com a comunidade do seu entorno. E5 (2014) diz "Acredito que há os dois lados. As questões sociais são abordadas durante boa parte da graduação, oportunizando aos alunos/educandos um olhar crítico a sua realidade. Mas tem sim um incentivo para que façamos que nossos alunos permaneçam no campo e produzindo, principalmente no que se refere às verbas repassadas ao curso". E4 (2014) coloca que "o curso vem de lutas dos movimentos sociais, de certa forma, as políticas usadas no mesmo são voltadas para questões sociais". E6 (2014) argumenta que "esteja voltada para as questões sociais, por se preocupar com mudanças da realidade do povo do campo". E3 (2014) de uma forma mais ampla também indica que o curso tende para as políticas sociais: "a educação do campo veio de lutas de movimentos sociais, entre eles MST,[...] por uma educação diferenciada, voltada para a realidade do campo, não essa educação imposta pelo sistema, que prepara para a vida urbana".

Nota-se na fala dos sujeitos que a relevância política para criação do curso é a questão social, uma vez que, indicam "[...] questões relevantes para a população e os agentes de referência a respeito do tema sobre o qual se participa" (Castellà \& Parés, 2012, p. 238).

Todavia, há de se considerar a presença da gestão estratégica, principalmente, na fala de E1 (2014), quando menciona que no curso são abordados assuntos com foco na produção para a subsistência e crescimento das comunidades, e não apenas para o lucro dos pequenos agricultores, fazendo, ainda, um contraponto com a lógica do agronegócio, este, voltado para a produção e o capital. E3 (2014) cita que o curso "[...] envolve em todos os sentidos, social, ambiental e econômico. Não tem como fugir do 
foco capitalista, porque é uma questão de sobrevivência, vivemos em um sistema que impõe essa forma de viver".

Nesse aspecto, verifica-se que a lógica predominante no campo é ainda a que Guerreiro Ramos (1989) chama de racionalidade instrumental, inserida nas relações entre os sujeitos que residem no campo, visto que há evidências de conflitos, tanto pessoais quanto interpessoais, sobre o que se deve ser e o que se pode ser, ou seja, na forma de produção dos pequenos agricultores e dos grandes ruralistas.

O curso, por meio daquilo que propõe, tenta conscientizar os acadêmicos sobre a necessidade de repassar aos alunos do campo a diferença entre uma e outra condição e, também, de pensar na comunidade, de melhorá-la, de aumentar sua própria qualidade de vida e inserção nos espaços sociais, e não apenas de buscar formas de aumento da produção, focada no mercado. Em outras palavras, trazer o sujeito para uma realidade mais substantiva. (Guerreiro Ramos, 1989).

Naquilo que diz respeito à capacidade de intervenção da administração local sobre o tema, em que "um processo participativo será mais eficiente se abordar temas sobre os quais a capacidade de intervenção da administração for muito grande" (Castellà \& Parés, 2012, p. 238), E1 (2014) e E2 (2014) citam a integração do curso, na medida do possível, ao sistema participativo do município. Ambos confirmam que os municípios nos quais 0 curso é ministrado contribuem significativamente para seu desenvolvimento. Todavia, a partir dos comentários, não é possível determinar em que medida aconteceu à intervenção da administração local no processo de implantação do curso.

Em relação ao tema ser oriundo de uma reivindicação cidadã, visto que "[...] não apenas respondem melhor à vontade dos cidadãos, mas também têm mais possibilidades de gerar processos bem-sucedidos, com maiores níveis de participação" (Castellà \& Parés, 2012, p. 238), E3 (2014) respondeu que "sim". E4 (2014) disse "Não exatamente da minha comunidade, mas sim por movimentos sociais os quais eu em particular apoio". E6 (2014) aponta que "de certa forma sim, pois se trata de um assentamento do MST." Tanto E1 (2014), quanto E2 (2014) consideram que sempre houve uma demanda da comunidade do campo pela educação. E5 (2014), por ser uma acadêmica "da cidade", traz outra perspectiva em suas palavras "então sou uma aluna oriunda da cidade, no entanto no início do curso era envolvida com a produção leiteira em Florianópolis, realizei minhas atividades em dois municípios distintos, um possui diretrizes específicas para Educação do Campo, algo que pesquisei e construí um artigo que demonstra que apesar das diretrizes, isso não foi demanda da comunidade e sim de uma pessoa da prefeitura, que em pesquisa na internet se interessou criou o programa e implementou atividades no contra turno e chamou isso de Educação do Campo".

A entrevistada 5 diz que "É claro que pensar nessa proposta e trazer para a escola é muito importante, entretanto a essência do que é a Educação do Campo em si, o qual considera a realidade de cada comunidade e seus sujeitos é deixado a margem. No outro município era uma escola no centro que recebia $40 \%$ dos alunos do meio rural e pouco trabalhava a realidade desses alunos" (E5,
2014). Observa-se a partir do posto que os sujeitos conheciam o objeto de participação, sua relevância e de onde provinha tal demanda, nesse sentido, acredita-se que o âmbito sobre o que se participa foi contemplado.

Vale destacar, ainda, a visão dos sujeitos sobre o processo em si. Em outras palavras, se 0 indivíduo sentiu-se fortalecido/amadurecido no sentido de capacitação para uma cultura política e participativa após a graduação E3 (2014) relata que "eu entrei uma pessoa e saí outra totalmente diferente. Muda totalmente a perspectiva. Ele faz com que o individuo se reconheça dentro da sociedade, conhecendo seus direitos. Você entra alienado pelo sistema e aqui você abre sua mente. Capacidade não só crítica, mas para a mudança. Crítico atuante, transformador". E4 (2014) diz que "sim, antes do curso não sabia o que realmente era política, a não ser a qual elegia determinados candidatos, que eu acreditava que era". E6, fala que "Sim, muito. Pois o curso nos ensina a entender as contradições da sociedade, bem como, o nosso lugar nessa contradição, nos ajudando a pensar estratégias que possam modificar essa estrutura por meio da educação, para que nossos estudantes também compreendam essas contradições e possam também pensar em mudanças, afinal um dos objetivos da escola é formar cidadãos críticos, infelizmente outros cursos de licenciatura não dão conta disso". Já E5, comenta que se afastou da área da educação "a graduação me tornou outra pessoa, com novas concepções e uma visão de mundo mais crítica, com certeza amadurecida. No entanto, me afastei das discussões e da área da educação, então, na prática não tenho contribuído".

Nota-se, a partir do dito pelos entrevistados, que a maioria dos egressos mantém suas relações com a comunidade, pois, entendese que os acadêmicos amadureceram durante o curso e assumiram o compromisso de atuação junto à escola e à comunidade.

Acredita-se que desde o planejamento até a implantação do curso houve influência cidadã do sujeito do campo, visto que as reivindicações pela educação no campo têm, pelo menos, em Santa Catarina, atingido gradativamente seus objetivos, exemplo desses resultados é a criação do curso de graduação em Licenciatura em Educação do Campo, que, de acordo com os entrevistados, além da formação de docentes favorece a capacitação para uma cultura política e participativa.

Contudo, apesar deste estudo ter tentando analisar a participação social no processo de implantação do curso de graduação em Licenciatura em Educação do Campo, tem-se que: definir qualidade na participação política é uma tarefa muito complexa. O próprio conceito de qualidade por si só é difícil de definir, pois pode expressar grande pluralidade e diversidade de significados. É um conceito abstrato, que geralmente se contrapõe ao conceito de quantidade para destacar precisamente os atributos ou propriedades positivas de alguma coisa ou processo (Anduzia \& De Maya citados por Castellà \&Parés, 2012, p. 218). Ou seja, o esforço em avaliar os dados coletados, no sentido de identificá-los nas dimensões sugeridas por Castellà \&Pares (2012), nas quais se acredita que podem verificar se o processo é ou não de qualidade, esbarra na dificuldade de mensurar a qualidade. 
Portanto, nesta pesquisa observou-se que dimensões como amplo envolvimento dos participantes, diversidade de participantes, representação dos atores, relevância política do tema, capacidade de intervenção da administração local sobre o tema e se o tema é oriundo de reivindicação cidadã foram contemplados no momento de planejamento e implantação do curso. Contudo, afirmar se houve ou não qualidade no processo seria uma conduta arriscada, uma vez que, conforme já dito, tentar medi-la é entrar no campo da complexidade. Todavia, considera-se que a participação, naquele momento, foi efetiva.

\section{CONSIDERAÇÕES FINAIS}

A educação é tema relevante em qualquer momento da história brasileira, principalmente, quando se trata de inseri-la de forma eficaz em locais que apresentam os mais baixos índices de escolaridade no país.

A partir de tal reflexão nasce o curso de graduação em Licenciatura em Educação do Campo da Universidade Federal de Santa Catarina, com o propósito de levar a educação para o campo, local onde o ensino, principalmente aquele referente ao ensino médio, é deficitário.

Nesse contexto, esta pesquisa analisou como aconteceu a participação social na implantação do Curso de Graduação em Licenciatura em Educação do Campo, em que se procurou conhecer as especificidades da educação no campo e averiguar como se deu a política e o processo de implantação do Curso de Graduação em Educação do Campo e, por fim aferir o alinhamento entre a implantação do curso e a participação social.

Assim, nas dimensões propostas, considerando o recorte temporal e os dados trabalhados na análise, entende-se que os critérios "quem participa?" e "sobre o que se participa?", estabelecidos por Castellá e Páres (2012), foram contemplados no momento de planejamento e implantação do curso.

Por outro lado, no que tange ao propósito de averiguar se a participação dos atores sociais envolvidos no processo atende a qualidade democrática dos processos administrativos, uma vez que, o curso nasce de uma reivindicação da comunidade do campo, entende-se que o esforço em avaliar os dados coletados, no sentido de enquadrá-los em dimensões pré-definidas, nas quais se acredita que poderão definir se o processo é ou não de qualidade, esbarra na dificuldade de mensurar a qualidade, visto que ela é complexa.

Todavia, acredita-se que os propósitos da educação do campo tentam promover aquilo que Santos e Meneses (2010) chamam de descolonialidade. Resumidamente, trata-se de uma libertação da dominação econômica e política, tanto em relação à hierarquização do saber, quanto naquilo que diz respeito à negação da diversidade.

Nesse contexto, entende-se que seria oportuna uma tentativa de retomada da participação dos movimentos sociais, a fim de promover a diversificação do olhar sobre o curso. Acredita-se que tal medida geraria o amadurecimento da dialogicidade e da participação, estes que são tidos como critérios essenciais em uma Gestão Social.

Quanto aos fatores limitadores da pesquisa aponta-se a redução sociológica do estudo, que segundo Guerreiro Ramos
(1996, p. 80), quando utilizado "como procedimento metodológico, é o esforço de tornar sistemática a assimilação crítica”. Assim, o foco local e específico deste estudo não o caracteriza como um estudo global, mas busca assimilar os conceitos e categorias teóricas a uma realidade específica.

Por fim, sugere-se para estudos futuros acerca deste tema, a busca pela compreensão aprofundada dos fatores que poderiam causar o distanciamento dos movimentos sociais, que representam as comunidades do campo, do acompanhamento das ações e políticas atualmente realizadas pela UFSC, quanto ao Curso de Licenciatura em Educação do Campo. A partir disso, pode-se trazer o olhar dos atores envolvidos, tratando tal problemática à luz da teoria da Gestão Social, no que tange o controle social, visto que esse curso é direcionado para as comunidades do campo.

\section{REFERÊNCIAS}

Anhaia, E. M. (2010). Constituição do movimento de educação do campo na luta por políticas de educação. Dissertação (Mestrado) - Universidade Federal de Santa Catarina, Centro de Ciências da Educação, Programa de PósGraduação em Educação, Florianópolis.

Arnstein, S. R. (2002). Uma escada da participação cidadã. 2002 Recuperado em: 20 outubro, 2014 de http://disciplinas.stoa.usp.br/pluginfile.php/80986/mod_resource/content/1/E scada\%20da\%20participa\%C3\%A7\%C3\%A3o.pdf

Brasil. (1988). Constituição da República Federativa do Brasil. Recuperado em: 20 novembro, 2014. /Recuperado em: 20 outubro 2014, de http://www.planalto.gov.br/ccivil_03/Constituicao/ConstituicaoCompilado.htm Ministério do Meio Ambiente. (2007). Agenda ambiental na administração pública. 4. ed. Brasília, DF: Ministério do Meio Ambiente.

Cançado, A. C., Sausen, J. O. \& Villela, L. E. (2013). Gestão social versus gestão estratégica. In: Tenório, F. G. (Org.). Gestão Social e Gestão Estratégica: experiências em desenvolvimento territorial. Rio de Janeiro: FGV.

Castellà, C. \& Parés, M. (2012). Participação e qualidade democrática: uma proposta de critérios de qualidade. In: Tenório, F. G. (Org.). Cidadania e desenvolvimento local: critérios de análise. Rio de Janeiro: Editora FGV.

Castilho, L. (2011). UFSC traz curso de licenciatura em educação do campo para o planalto norte. Recuperado em: 20 novembro, 2014, de http://www.luciomarcastilho.com.br/ufsc-traz-curso-de-licenciatura-emeducacao-do-campo-para-o-planalto-norte/.

Cruz Júnior, J. B. (1988). Organização e Administração de entidades públicas: Aspectos Econômicos, Políticos e Sociais de um Paradigma Emergente. Revista de Administração Pública. Rio de Janeiro. Fundação Getúlio Vargas, 22(3): 3-21, jul./set.

Godoy, A. S. (1995). Introdução à pesquisa qualitativa e suas possibilidades. Revista de Administração de Empresas. São Paulo, v. 35, n. 2, p. 57-63, março/abril.

Guerreiro Ramos, A. G. (1989). A nova ciência das organizações. Tradução Mary Cardoso. 2.ed. Rio de Janeiro: Editora Fundação Getúlio Vargas. (1996). Redução sociológica. Rio de Janeiro: Editora UFRJ, 1996. Estudo de caso qualitativo. In: Godoi, C.K; Bandeira-de-Melo, R. Silva, A. B. (Org.). (2006). Pesquisa Qualitativa em Estudos Organizacionais paradigmas, estratégias e métodos. São Paulo: Saraiva.

IBGE. Instituto Brasileiro de Geografia e Estatística. (2013). Síntese de indicadores sociais: uma análise das condições de vida da população brasileira (2002-2012). Recuperado em: 12 dezembro, 2014, de

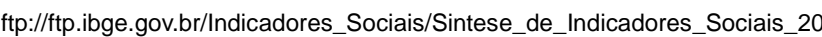
13/pdf/educacao_pdf.pdf.

INCRA. (2014). Instituto Nacional de Colonização e Reforma Agrária. Recuperado em: 20 novembro, 2014, de http://www.incra.gov.br/content/educacao-no-campopronera.

Molina, M. C. Prefácio. In: Aued, B. W; Vendramini, C. R. (2009). Educação do campo: desafios teóricos e práticos. Florianópolis: Insular.

Oliveira, M. M. de. (2007). Como fazer pesquisa qualitativa. Petrópolis, RJ Vozes.

Paraná. (2006). Diretrizes Curriculares do Estado. Educação do Campo: SEED. Recuperado em 20 novembro, 2014 http://www.cfwsantosdumont.seed.pr.gov.br/redeescola/escolas/6/344/24/arq uivos/File/complementacao1.doc.

Perardt, S. Análise do processo de criação das atividades de ensino na implantação do Campus de Araranguá da Universidade Federal de Santa Catarina sob a ótica da gestão social. (2013). 242 p. Dissertação (Mestrado profissional) - Universidade Federal de Santa Catarina, Centro Sócio- 
Econômico, Programa de Pós-Graduação em Administração Universitária, Florianópolis.

Polanyi, K. (2000). A grande transformação: as origens da nossa época. 2.ed. Rio de Janeiro: Campus.

REUNI. Ministério da Educação. Reestruturação e Expansão das Universidades Brasileiras: Diretrizes Gerais. (2007). Recuperado em 21 novembro, 2014,

http://portal.mec.gov.br/sesu/arquivos/pdf/diretrizesreuni.pdf.

Santos, B. S. \& Meneses, M. P. (2010). Epistemologias do Sul. São Paulo: Editora Cortez.

Tenório, F. G. Inovando com democracia, ainda uma utopia. (1999). In: Novos Cadernos NAEA Belém, NAEA (Núcleo de Altos Estudos da Amazônia)/UFPA, v. 2, n. 1, p. 149 -162, jun.

UNESCO; CNBB; UNICEF, MST; UNB. (Orgs.) (1998). Conferencia Nacional por uma Educação Básica do Campo: texto base. Recuperado em 20 novembro,

2014 ,
Universidade Federal de Santa Catarina. (2009). Resolução no 006, de 01 de abril de 2009. Cria o Curso de Graduação em Educação do Campo modalidade Licenciatura do Centro de Ciências da Educação - CED. Florianópolis, SC.

Curso de Licenciatura em Educação do Campo. (2013a). Recuperado $\overline{\text { em } 20}$ novembro, 2014, de http://licenciatura.educampo.ufsc.br/

Licenciatura em Educação do Campo da UFSC forma primeira turma. (2013b). Recuperado em 20 novembro, 2014, de http://noticias.ufsc.br/2013/09/licenciatura-em-educacao-do-campo-da-ufscforma-primeira-turma/

Projeto Pedagógico do Curso de Graduação em Licenciatura Em Educação do Campo. (2014). Recuperado em 20 novembro, 2014, de http://ledoc.paginas.ufsc.br/files/2014/08/PPP-LEdoC.pdf

Vergara, S. C. (2007). Projetos e relatórios de pesquisa em administração. 8.ed. São Paulo: Atlas. 